\title{
Change in haematological and selected biochemical parameters measured in feline blood donors and feline whole blood donated units
}

\author{
Eva Spada, Daniela Proverbio, Luciana Baggiani, Giada Bagnagatti De Giorgi, Elisabetta Ferro and \\ Roberto Perego
}

Department of Health, Animal Science and Food Safety (VESPA), Unit of Veterinary Transfusion Medicine (REV), University of Milan, Milan, Italy

This work was presented at the LXIX Società Italiana delle Scienze Veterinarie (SISVet) Annual Congress, 15-17 June 2015, Perugia, Italy.

Corresponding author: Eva Spada DVM, PhD, University of Milan, via G. Celoria, 10-20133 Milan, Italy, Email: eva.spada@unimi.it

\begin{abstract}
Objectives The quality of whole blood (WB) units is influenced by many factors, starting with selection of donors and the method of blood collection. The aim of this study was to investigate the changes that occur in haematological and selected biochemical parameters in blood transferred from a feline blood donor to feline WB unit. Methods Data from 27 feline blood donations were used in this study. Cats were anaesthetised with a combination of tiletamine and zolazepam. Blood (10 ml/kg body weight to a maximum of $60 \mathrm{ml} / \mathrm{cat}$ ) was collected in citratephosphate-dextrose-adenine (CPDA) anticoagulant. Lactated Ringer's solution $(10 \mathrm{ml} / \mathrm{kg}$ ) was administered intravenously starting halfway through the donation. Haematological and selected biochemical parameters (complete blood count, free haemoglobin, \% haemolysis, glucose, sodium, potassium, $\mathrm{pH}$ ) were measured in the blood donor before donation and in the corresponding donated WB unit soon after collection.
\end{abstract}

Results Significant decreases occurred between blood donor and WB unit in red blood cells (mean difference $-1.06 \times$ $10^{12} / \mathrm{l} ; P<0.0001$ ), haemoglobin (mean difference $-1.6 \mathrm{~g} / \mathrm{dl} ; P<0.0001$ ), haematocrit (mean difference $-4.6 \% ; P$ $<0.0001$ ), red cell distribution width (mean difference $-0.9 \% ; P=0.0003$ ), white blood cells (mean difference $-2.17 \times$ $10^{9} / \mathrm{l} ; P<0.0001$ ), $\mathrm{pH}$ (mean difference $-0.5 ; P<0.0001$ ) and potassium (mean difference $-1.4 \mathrm{mmol} / \mathrm{l} ; P<0.0001$ ). Significant increases occurred between blood donor and WB unit in platelets (mean difference $+87.00 \times 10^{9} / \mathrm{l} ; P=$ 0.0039 ), glucose (mean difference $+25.42 \mathrm{mmol} / \mathrm{l} ; P<0.0001$ ) and sodium (mean difference $+20 \mathrm{mmol} / \mathrm{l} ; P<0.0001$ ).

Conclusions and relevance When using a blood collection protocol with intravenous fluid administration midway through the donation and a CPDA:blood ratio of 1:7, there were significant changes in both the haematological and biochemical characteristics between the blood donors and WB units. The majority of these changes may be the result of the anticoagulants used for storage. Understanding these changes may assist selection of blood donors and help prediction of the characteristics of the donated WB unit.

Accepted: 2 January 2016

\section{Introduction}

Blood transfusion and blood banking are a relatively new area of specialisation in veterinary medicine. Since feline blood typing became available in the 1990s, feline transfusion medicine has become more widespread, and whole blood and blood components have become commercially available and more cats have been enrolled in blood donor programmes. ${ }^{1,2}$

Collection of a conventional unit of feline blood is now commonplace in veterinary blood banks and practices, and recipient cats typically receive fresh or stored whole blood (WB). A conventional feline WB unit typically contains a total volume of $60 \mathrm{ml}$. Open systems are often used for blood collection in cats as closed systems are not readily available commercially. If collected for storage, the WB is transferred aseptically to a transfer pack container (50-150 ml capacity) 
and sealed to protect against bacterial contamination. Newer collection systems from commercial blood banks provide a syringe, butterfly catheter, three-way stopcock, and single- or double-storage bags as a single autoclaved unit ready for use. Anticoagulant must still be added through the injection port before collection with these systems. ${ }^{3}$ The anticoagulant most commonly used is citrate-phosphate-dextrose-adenine (CPDA) solution used at a ratio of $1 \mathrm{ml}$ per 6-9 $\mathrm{ml}$ whole blood. ${ }^{1,4-6}$

Several studies have reported the health status of feline donors, but there is little published on the quality of feline blood units in comparison with other species such as dogs and horses. ${ }^{7-10}$ To our knowledge, there are no reports on the changes occurring in blood during the transfer from the feline donor to feline WB unit. The aim of this study was to document changes in haematological and selected biochemical parameters from the feline blood donor to a WB unit using a previously described blood donation protocol. ${ }^{11}$ In our previously study, ${ }^{11}$ using identical anaesthetic and fluid protocols, haemato- logical parameters in the feline donor did not change significantly before and after the blood donation; we therefore hypothesised that haematological parameters would not change significantly between donor and WB unit but that significant changes could occur in biochemical parameters owing to the characteristics of the anticoagulant preservative solution used in WB units.

\section{Materials and methods}

\section{Animals and samples}

Data from 27 suitable feline blood donors (15 males and 12 females, all European domestic shorthair cats with a mean weight of $5.1 \mathrm{~kg}$ [range 4.5-7.0 kg], a mean age of 5.7 years [range 2-8 years]) and from the individual donated WB units were used in this study. Data were derived from routine monitoring of the blood donor procedure and quality control of the WB units produced and used for clinical purposes at the Veterinary Transfusion Unit of the University of Milan, Milan, Italy. Written owner consent was obtained for blood collection, and for the use of blood samples and all data for scientific purposes each time a cat visited the clinic during routine pre blood donation visits.

The blood donation protocol was as previously described. ${ }^{11}$ Briefly, cats were anaesthetised with $2.5 \mathrm{mg} / \mathrm{kg}$ tiletamine and $2.5 \mathrm{mg} / \mathrm{kg}$ zolazepam (Zoletil 100; Virbac) intramuscularly. After induction, the cats were placed in lateral recumbency on a heat electric blanket, and ophthalmic lubricant was applied. A 20-22 G intravenous (IV) catheter was placed in the cephalic vein, and a predonation blood sample $(1.5 \mathrm{ml}$ in EDTA tube and $1.5 \mathrm{ml}$ in

serum tube) was collected. Next, $90 \mathrm{ml}$ lactated Ringer's solution was administered subcutaneously. Systolic arterial pressure, mean arterial pressure, diastolic arterial pressure and heart rate were measured with an oscillometric device by applying the cuff to the tail base of each cat. A small area on the ventral neck was clipped to expose the left jugular vein and was disinfected with three stokes of isopropyl alcohol.

Blood donation was from the jugular vein. Blood (10 ml/kg to a maximum volume of $60 \mathrm{ml}$ ) was collected, via a $19 \mathrm{G}$ butterfly needle, into $20 \mathrm{ml}$ syringes containing CPDA anticoagulant (composition for $63 \mathrm{ml}: 2000 \mathrm{mg}$ dextrose, $17.3 \mathrm{mg}$ adenine, $1660 \mathrm{mg}$ trisodium citrate, $206 \mathrm{mg}$ citric acid, $140 \mathrm{mg}$ sodium phosphate) in a ratio of CPDA:blood of 1:7 as previously described. ${ }^{4,5}$ Lactated Ringer's solution at $10 \mathrm{ml} / \mathrm{kg}$ was administered intravenously by rapid infusion starting halfway through the donation. Blood collection was completed within 3-5 mins.

Blood from the syringes was than transferred to a $150 \mathrm{ml}$ empty transfer bag (Transfer Grifols 150; Grifols Italia SpA) using a spike (Combifix Adapter; B Braun Vet Care $\mathrm{GmbH}$ ) connected to the bag segment. The blood in the bag was gently mixed for 2 mins and 2-3 tube segments (pigtails) were created with an electric thermal sealer (Hemoweld-B; Delcon Medical Devices). One of the segments containing approximately $1.5 \mathrm{ml}$ of blood was removed, and the blood transferred to an empty tube for analysis.

\section{Laboratory tests}

For this study each of the following haematological parameters was measured in the anaesthetised blood donor (on EDTA sample) before the blood donation and in the corresponding donated WB units (on CPDA sample): complete blood count (CBC) using a Cell-Dyn 3500 haematology analyser (Abbott Diagnostic Laboratories), evaluating red blood cells (RBCs), haemoglobin $(\mathrm{Hb})$, haematocrit $(\mathrm{Hct})$, mean cell volume (MCV), mean cell $\mathrm{Hb}(\mathrm{MCH})$, mean cell Hb concentration $(\mathrm{MCHC})$, red cell distribution width (RDW) and white blood cells (WBCs). The platelet (PLT) count was assessed 
microscopically at oil immersion $\times 100$ magnification on air-dried Wright- Giemsa-stained blood films. PLT numbers were estimated by multiplying the average number per 10 fields by 15,000 to get the approximate number of PLT per $\mathrm{ml}$ of blood.

After the CBC was performed, EDTA samples from blood donors and CPDA samples from WB units were centrifuged at $3500 \times g$ for 10 mins and free $\mathrm{Hb}$ and \% haemolysis were measured in the supernatant (plasma). Hb concentration in the supernatant was determined using a Cell-Dyn 3500 automatic analyser. The Hb detection range of the Cell-Dyn 3500 was $0-24 \mathrm{~g} / \mathrm{dl}^{12}$

Haemolysis was calculated using the following formula: ${ }^{7-10,13}$

$\%$ Haemolysis $=(100$ haematocrit $) \times$ supernatant $($ plasma $)$ haemoglobin $(\mathrm{g} / \mathrm{dl}) /$ total haemoglobin $(\mathrm{g} / \mathrm{dl})$

Table 1 Mean or median \pm SD, 95\% confidence interval $(\mathrm{Cl})$ and mean difference between haematological parameters

measured in feline blood donors and feline whole blood (WB) donated units

\begin{tabular}{|c|c|c|c|c|c|}
\hline $\begin{array}{l}\text { Haematological } \\
\text { parameter }\end{array}$ & $\begin{array}{l}\text { Normal feline RI for Cell- } \\
\text { Dyn } 3500\end{array}$ & $\begin{array}{l}\text { Mean or median } \pm \text { SD }(95 \% \mathrm{Cl}) \\
\text { in blood donor }\end{array}$ & $\begin{array}{l}\text { Mean or median } \pm \text { SD }(95 \% \\
\text { CI) in WB unit }\end{array}$ & $\begin{array}{l}\text { Mean } \\
\text { difference }\end{array}$ & $P$ value \\
\hline RBCs $\left(\times 10^{12} / \mathrm{I}\right)$ & $6.56-11.20$ & $7.51 \pm 0.94(7.14-7.88)$ & $6.45 \pm 1.09(6.02-6.88)$ & -1.06 & $<0.0001$ \\
\hline HCT (\%) & $31.7-48.0$ & $30.7 \pm 4.7(28.8-32.5)$ & $26.1 \pm 4.4(24.4-27.9)$ & -4.6 & $<0.0001$ \\
\hline $\mathrm{Hb}(\mathrm{g} / \mathrm{dl})$ & $10.6-15.6$ & $10.6 \pm 1.5(9.9-11.2)$ & $8.9 \pm 1.7(8.3-9.6)$ & -1.6 & $<0.0001$ \\
\hline Free $\mathrm{Hb}(\mathrm{g} / \mathrm{dl})$ & - & $0.03 \pm 0.04(0.03-0.05)$ & $0.04 \pm 0.03(0.02-0.05)$ & +0.01 & 0.5826 \\
\hline Haemolysis (\%) & - & $0.28 \pm 0.19(0.19-0.36)$ & $0.37 \pm 0.28(0.26-0.49)$ & +0.1 & 0.1423 \\
\hline MCV (fl) & $36.7-53.7$ & $41.1 \pm 3.9(39.5-42.6)$ & $40.7 \pm 4.2(39.1-42.4)$ & -0.3 & 0.4490 \\
\hline $\mathrm{MCH}(\mathrm{pg})$ & $12.3-17.3$ & $14.1 \pm 1.8(13.4-14.8)$ & $14.0 \pm 1.7(13.0-15.1)$ & +0.1 & 0.8956 \\
\hline $\mathrm{MCHC}(\mathrm{g} / \mathrm{dl})$ & $30.1-35.6$ & $34.5 \pm 2.8(33.4-35.6)$ & $34.4 \pm 2.0(33.6-35.2)$ & -0.1 & 0.7670 \\
\hline RDW (\%) & $16.7-22.9$ & $17.6 \pm 1.5(17.1-18.2)$ & $16.7 \pm 1.6(16.1-17.4)$ & -0.9 & 0.0003 \\
\hline PLTs $\left(\times 10^{9} / \mathrm{I}\right)$ & $175.00-500.00$ & $\begin{array}{l}246.00 \pm 156.00 \quad(184.00- \\
308.00)\end{array}$ & $-333.00 \pm 210.00$ & +87.00 & 0.0039 \\
\hline WBCs $\left(\times 10^{9} / \mathrm{I}\right)$ & $4.04-18.70$ & $7.14 \pm 1.85(6.40-7.87)$ & $4.87 \pm 1.73(4.17-5.60)$ & -2.17 & $<0.0001$ \\
\hline
\end{tabular}

Values in bold are statistically significant

$\mathrm{RI}=$ reference interval; $\mathrm{RBCs}=$ red blood cells; $\mathrm{HCT}=$ haematocrit; $\mathrm{Hb}=$ haemoglobin; $\mathrm{MCV}=$ mean cell volume; $\mathrm{MCH}=$ mean cell haemoglobin;

$\mathrm{MCHC}=$ mean cell haemoglobin concentration; RDW = red cell distribution width; PLTs = platelets; WBCs = white blood cells

Biochemical parameters including glucose, sodium, potassium and $\mathrm{pH}$ were evaluated in serum samples from the blood donor and in CPDA plasma samples from WB units. Glucose, measured spectrophotometrically, was determined using an automated analyser (COBAS MIRA Classic; Roche Analytical Instruments). Sodium and potassium were measured with a flame photometer (IL 943; Instrumentation Laboratory).

\section{Analysis and statistics}

Data were tested for normal distribution using the Kolmogorov-Smirnov test. Mean values with SD and 95\% confidence interval $(\mathrm{Cl})$ were calculated for normally distributed data and the median was used for non-normally distributed data. Differences between parameters in the blood donor and blood unit were tested with a Student's $t$-test or Wilcoxon test according to whether or not the data were normally distributed. All statistical calculations were performed with MedCalc software (version 12.7.0). Results were considered significant when $P<0.05$.

\section{Results}

Mean value \pm SD or median and $95 \% \mathrm{Cl}$ of all parameters considered in the donor and blood unit and mean difference between donor and unit with $P$ values are reported in Table 1 for haematological data and in Table 
2 for biochemical data. PLT aggregation and thrombocytopenia were noted at microscopy in five EDTA samples but not in the corresponding CPDA WB unit samples.

Significant decreases occurred in RBC count, $\mathrm{Hb}$ concentration, $\mathrm{Hct}, \mathrm{RDW}, \mathrm{WBC}$ count, $\mathrm{pH}$ and potassium concentration between blood donor and blood unit. Significant increases occurred between blood donor and blood unit for PLT count, glucose concentrations and in sodium concentrations.

Mean values of RBCs, HB, Hct, glucose, $\mathrm{pH}$, sodium and potassium in the blood units were outside the normal feline reference interval for these parameters.

\section{Discussion}

The final quality of WB units and haemocomponents depends on a variety of factors starting with the selection of donors and the method of blood collection. In the present study several blood parameters changed between feline blood donor and blood unit. Most of these changes can be attributed to the characteristics of the anticoagulant preservative solution used but may also be influenced by the IV fluid therapy that started halfway through the blood donation. The anticoagulant preservative solution most commonly used for blood col- lection and storage in veterinary medicine is CPDA, ${ }^{1,4-6}$ which contains citrate, phosphate, dextrose and adenine. Citrate and citric acid chelate calcium prevent blood coagulation, as well as retard glycolysis. Monobasic sodium phosphate maintains $\mathrm{pH}$ during storage and is necessary for maintenance of adequate levels of 2,3-diphosphoglycerate. Dextrose is the substrate for adenosine triphosphate (ATP) production and therefore cellular energy. Finally, adenine provides RBCs with the

Table 2 Mean or median \pm SD, 95\% confidence interval $(\mathrm{Cl})$ and mean difference between selected biochemical parameters measured in feline blood donors and feline whole blood (WB) donated units

\begin{tabular}{|l|l|l|l|l|l|}
\hline $\begin{array}{l}\text { Biochemical } \\
\text { parameter }\end{array}$ & $\begin{array}{l}\text { Normal feline } \\
\text { RI }\end{array}$ & $\begin{array}{l}\text { Mean or median } \pm \text { SD }(95 \% \mathrm{Cl}) \\
\text { blood donor }\end{array}$ & $\begin{array}{l}\text { Mean or median } \pm \text { SD }(95 \% \mathrm{Cl}) \text { in } \\
\text { WB unit }\end{array}$ & $\begin{array}{l}\text { Mean } \\
\text { difference }\end{array}$ & $P$ value \\
\hline Glucose $(\mathrm{mmol} / \mathrm{l})$ & $3.16-7.27$ & $5.11 \pm 0.94(4.72-5.55)$ & $30.47 \pm 4.27(28.69-32.25)$ & +25.42 & $<0.0001$ \\
\hline $\mathrm{pH}$ & $7.28-7.41$ & $8.0 \pm 0.4(8.0-8.2)$ & $7.6 \pm 0.5(7.5-7.8)$ & -0.5 & $<0.0001$ \\
\hline Sodium $(\mathrm{mmol} / \mathrm{l})$ & $150.0-160.0$ & $158.0 \pm 8.6(155.0-162.0)$ & $178 \pm 6.0(176-181)$ & +20 & $<0.0001$ \\
\hline Potassium $(\mathrm{mmol} / \mathrm{l})$ & $3.5-5.5$ & $4.5 \pm 0.5(4.3-4.7)$ & $3.1 \pm 0.3(3.0-3.2)$ & -1.4 & $<0.0001$ \\
\hline
\end{tabular}

Values in bold are statistically significant $\mathrm{RI}=$ reference interval

substrate for their metabolism, thus improving RBC viability. ${ }^{7,8,14}$ This anticoagulant preservative solution is used in ratios from 1:7 to 1:9 CPDA:blood, ${ }^{4,5}$ and is often also used as an anticoagulant and preservative solution for feline WB storage, ${ }^{6,15}$ as in our study.

The high dextrose content in CPDA anticoagulant preservative solution (2000 mg dextrose in $63 \mathrm{ml}$; ie, $31.8 \mathrm{mg} / 1 \mathrm{ml}$ ) resulted in the very high supernatant glucose concentrations in the blood units. The mean value of glucose concentration in our feline WB units was $30.47 \mathrm{mmol} / \mathrm{l}$, and this finding should be considered when the WB unit is used in diabetic or ketoacidotic anaemic patients. In this study the highest glucose con- centration measured in a WB unit was $43.96 \mathrm{mmol} / \mathrm{l}$. Assuming a feline blood volume of $62-66 \mathrm{ml} / \mathrm{kg}$, with a mean of $64 \mathrm{ml} / \mathrm{kg}^{16}$ the serum glucose concentration in a $4 \mathrm{~kg}$ cat receiving one WB unit (approximately $60 \mathrm{ml}$ ) with a glucose concentration of $43.96 \mathrm{mmol} / \mathrm{l}$ would be expected to increase by $10.32 \mathrm{mmol} / \mathrm{l}$. RBCs use glucose as a substrate for anaerobic glycolysis to generate ATP. ${ }^{7,8,14}$ Moreover, glucose concentration in WB did not fall with time. High concentrations were present immediately after collection and persisted for 35 days through- out WB storage (results not shown). This high glucose concentration in the WB unit should be borne in mind when diabetic or ketoacidotic anaemic cats are trans- fused with WB units collected with CPDA anticoagulant. In these animals we recommended monitoring of post- transfusion blood glucose concentrations in case insulin doses need to be increased to control hyperglycaemia. Heparin may be a more appropriate anticoagulant for blood collection if WB units are intended for anaemic diabetic cats. However, there are a number of disadvantages of heparin: it activates PLT adhesion and aggregation and inhibits thrombin formation and factor IX activation. Furthermore, heparin has no preservative properties. ${ }^{17}$ Another alternative for diabetic cats, if blood is to be administered within a day of collection, is sodium citrate $(1 \mathrm{ml} 3.13 \% \text { sodium citrate per } 9 \mathrm{ml} \mathrm{blood})^{17}$ as it has no effect on PLT function, although this also has no preservative effect on RBCs. 
The higher sodium content in feline blood units could be due to the sodium salts in the CPDA anticoagulant. In fact, 1 $\mathrm{ml}$ CPDA contains $26.4 \mathrm{mg}$ trisodium citrate and $2.2 \mathrm{mg}$ sodium phosphate resulting in increased final measured sodium values in the blood units, with a mean value \pm SD of $178 \pm 6.0$ and a mean difference between donor and unit of +20 $\mathrm{mmol} / \mathrm{l}$.

It is important to maintain $\mathrm{pH}$ in the physiological range for ATP synthesis. A pH $\geqslant 6.2$ is required for continued RBC metabolism in stored blood and $\mathrm{a} \mathrm{pH} \geqslant 6.65$ is required for human blood used for transfusion. ${ }^{18}$ The $\mathrm{pH}$ of feline venous blood is normally between 7.28 and 7.41. ${ }^{19}$ Our feline blood donors had a higher blood pH (median \pm SD, 8.0 \pm 0.4 ), possibly owing to the fact that blood samples were taken from anaesthetised cats. Anaesthesia with a combination of zolezepam and tiletamine causes hypoventilation in cats, ${ }^{20}$ resulting in acidosis. However, our anaesthetic protocol used a very low dose of this anaesthetic combination (ie, $2.5 \mathrm{mg} / \mathrm{kg}$ tiletamine and zolazepam) and blood samples were collected from feline donors within a few minutes of anaesthetic induction. With this low dose of anaesthetic hyperventilation was initially noted in our feline blood donors. This might result in blood alkalosis. The significant decrease in $\mathrm{pH}$ noted between donor and unit (unit $\mathrm{pH}$ median $\pm \mathrm{SD}, 7.6 \pm 0.5$, mean difference from blood donor -0.5 ; $P<0.0001)$ may have been the result of the buffering capacity of CPDA. The decrease in $\mathrm{pH}$ values in the blood units was likely due to the citric acid in the CPDA solution, which has a $\mathrm{pH}$ of 5-6.

The mean value of RBCs, Hct, Hb and WBCs in WB units dropped significantly from that of the blood donor, and this could be the result of the dilution effect of the combination of IV fluid therapy used in our donation protocol and amount of CPDA..$^{4,5}$ In fact, in a previous study in which the same anaesthetic and IV fluid protocol was used in blood donors, ${ }^{11}$ RBC count, Hct, HB and WBC count decreased in the blood donor after donation; however, these reductions did not reach statistical significance. Therefore, in the previous study in which the same fluid and anaesthetic protocol was used in the blood donor, the haematological variables did not decrease significantly in the donor cat but they did when comparing the values in the blood donors to the WB unit in this study.

As Hct is an important characteristic of WB units (as these are used mainly for anaemic cats) and in this study there was a statistically significant mean reduction in $\mathrm{Hct}$ of $-4.6 \%$, it might be preferable to use an anticoagulant:blood ratio of 1:9 rather than 1:7 in order to obtain a higher $\mathrm{Hct}, \mathrm{RBC}$ count and $\mathrm{Hb}$ content in the WB units. Because a fixed amount of blood is collected from the donor $(10 \mathrm{ml} / \mathrm{kg}$ with a maximum of $60 \mathrm{ml} / \mathrm{cat})$ the net effect on the recipient would be no different as the total number of RBCs transfused would be unchanged. The only difference would be the volume of CPDA. For $60 \mathrm{ml}$ of blood a ratio of $1: 7$ would be $8.6 \mathrm{ml} \mathrm{CPDA}$ and of 1:9 would be $6.7 \mathrm{ml}$ of CPDA. As $8.6 \mathrm{ml}$ of CPDA results in a mean/median value for $\mathrm{Hct} / \mathrm{Hb} / \mathrm{RBC}$ count in the WB units of $26.1,8.9$ and 6.45 , respectively, we calculated that $1.9 \mathrm{ml}$ of CPDA less in the WB unit would result in a mean/median increase of $\mathrm{Hct} / \mathrm{Hb} / \mathrm{RBC}$ count of $5.8,2.0$ and 1.43 , respectively.

However, the effect of the fluid therapy and of the anaesthetic protocol on the haematological parameters studied should also be considered. Relative to the potential effects of the subcutaneous fluids, every cat in this study received $90 \mathrm{ml}$ lactated Ringer's solution subcutaneously immediately before blood donation. The smallest cat in the study weighed $4.5 \mathrm{~kg}$ and would have received $20 \mathrm{ml} / \mathrm{kg}$ fluids, while the largest cat ( $7 \mathrm{~kg}$ ) would have received approximately $13 \mathrm{ml} / \mathrm{kg}$. This difference should not have influenced the haematological and biochemical results. The mean time to complete the full blood donation procedure in this study, including time for pre- and post-donation evaluation, was $<40$ mins, with a mean duration of $39 \pm 11$ mins (range $24-76$ mins)..${ }^{11}$ In this time the subcutaneous fluid should not have influenced haematological parameters significantly. In support of this, the smallest cats did not have greater falls in Hct and RBC count than the heaviest cats.

In addition, anaesthesia could have influenced the haematological parameters. The effects of tiletamine/ zolazepam intramuscularly on haematological parameters were assessed in female dogs submitted for ovariohysterectomy. ${ }^{21}$ Lacerda et al showed that the values for RBC count, Hb, Hct, MCV and WBC count, reduced 60 mins after administration of tiletamine/zolazepam and were normalised again after $24 \mathrm{~h} .{ }^{21}$ This effect of tiletamine/zolazepam combination on canine haematological parameters might explain the significant modification of haematological parameters in our feline blood donors. However, additional studies on the effect of tiletamine and zolazepam on haematological parameters are needed to confirm this hypothesis and the timing and magnitude of these effects on anaesthetised feline

patients. In support of this hypothesis, a previous study by Dhumeaux et al demonstrated that in healthy cats fol- lowing induction of general anaesthesia with a ketamine-based anaesthetic protocol of IV ketamine and midazolam and intramuscular buprenorphine, there was a significant change in circulating erythrocytes in cats, characterised by decreases in RBC count, $\mathrm{Hb}$ con- centration and Hct. ${ }^{22}$ However, anaesthesia alone could not have caused the drop in 
$\mathrm{Hct} / \mathrm{Hb} / \mathrm{RBC}$ count seen in our donor cats as the same anaesthetic protocol with zolazepam and tiletamine did not result in a statistically significant change in these parameters when evaluated in blood donors before and after blood donation. ${ }^{11}$

PLT counts increased significantly in the WB units compared with the blood donors. PLT clumping is often observed in feline blood samples, even those from nor- mal cats. ${ }^{23}$ Aggregation of PLTs in feline blood samples makes it difficult to assess PLT number, regardless of the laboratory method used. ${ }^{24}$ As a consequence, if aggregation occurs the PLT count for feline samples is often inaccurate, regardless of the laboratory method used. EDTA is the preferred anticoagulant for $\mathrm{CBC}$ determination in most species and is the anticoagulant we used for collection of samples from blood donors. However, PLT aggregates may occur even in EDTA-anticoagulated blood samples collected under ideal conditions; if so, collection of blood using another anticoagulant (eg, cit- rate) may prevent cell aggregation. ${ }^{25}$ For example, the decreased PLT clumping produced by the anticoagulant citrate-theophylline-adenosine-dipyridamole (CTAD) resulted in higher PLT counts, regardless of the technique. The concentration of adenosine in CTAD is high and falls within the range at which adenosine inhibition of feline PLT aggregation occurs. ${ }^{26}$ Adenosine activates adenylcyclase, which catalyses cyclic adenosine monophosphate (CAMP) production from ATP. cAMP keeps PLTs in a resting state by regulating the sequestration of calcium in intracytoplasmic organelles. ${ }^{27}$ In one study PLT counts were significantly higher $(P<0.001)$ in samples containing CTAD than in samples with EDTA. ${ }^{28}$ This may also have been the case in the samples from our blood unit with citrate as the anticoagulant, in which at least five showed no PLT aggregation in comparison with the respective EDTA sample from the blood donor. The fact that blood for haematological analysis from the donor cat was collected into EDTA and the blood from the WB unit was in CPDA could therefore have influenced the PLT count. However, the citrate, sodium and dextrose content of CPDA could have influenced most of the biochemical parameters studied.

Markers of membrane damage and lysis of RBCs include plasma $\mathrm{Hb}$, plasma potassium and intracellular enzymes, such as lactate dehydrogenase, which are released into plasma from the lysed RBCs. Haemolysis is the most acute marker of red cell membrane damage and it more commonly results from in vitro erythrocyte dam- age associated with improper sample handling and col- lection. ${ }^{29}$ The degree of haemolysis is described as the percentage of free $\mathrm{Hb}$ in relation to the total $\mathrm{Hb}$, with appropriate correction for the Hct. In human transfusion medicine free $\mathrm{Hb}$ in blood units should not exceed $0.4 \mathrm{~g} / \mathrm{dl}$ or $0.8 \%$ of total $\mathrm{Hb} .{ }^{13}$ In the feline blood units collected in $20 \mathrm{ml}$ syringes in our study there was minimal haemolysis, with a mean total haemolysis value of $0.37 \%$. Thus, it appears that collection with a $20 \mathrm{ml}$ syringe using a large $19 \mathrm{G}$ butterfly needle minimises the shearing forces that physically damage RBCs as they flow through the needle.

Feline WB units in our study showed a significantly lower potassium concentration (mean \pm SD $3.1 \pm 0.3$ ) than found in the blood donors ( $4.5 \pm 0.5$ ). Dilution of plasma potassium concentration by giving potassium-free fluids, especially those containing glucose, may contribute to hypokalaemia. In our donation protocol the donor received $10 \mathrm{ml} / \mathrm{kg}$ lactated Ringer's solution, which has relatively low potassium levels (potassium concentration $4 \mathrm{mEq} / \mathrm{l}$ ), halfway through the blood donation. Another possible explanation for the low potassium concentration in feline WB units could be the translocation of potassium from plasma into cells due to the high dextrose content of the CPDA anticoagulant. ${ }^{19}$

In our opinion, the characteristics and volume of the CPDA anticoagulant preservative solution used for blood collection was the major cause of the haematological and biochemical changes, as haematological parameters in pre- and postdonation samples did not change significantly in a previous study using the same anaesthetic and fluid therapy protocol. However, because there is no study comparing anticoagulants, it is difficult to confirm that CPDA (and not the collection process or some other physiological process) is the cause of the change in the donor cats and this could be considered a limitation of this study. The fluid therapy and anaesthetic protocol used in this blood donation protocol could also contribute to the haematological and bio- chemical alterations seen.

\section{Conclusions}

The results of this study show that feline blood under-goes haematological and biochemical changes as it is transferred from blood donor to WB unit. The haematological changes could explain why the expected percent- age increase in packed cell volume (PCV) following WB transfusion in cats is often not realised, in particular when blood donor PCV has been used to calculate the expected post-transfusion PCV of the blood recipient. ${ }^{6}$ Clinicians may find the results of this study useful when selecting feline blood donors; for example, understanding the benefits in choosing the blood donor with the highest Hct, or an anticoagulant with no dextrose con- tent for diabetic anaemic patients, or using a different

fluid therapy or anaesthetic protocol in the blood donor. In vivo studies are needed to verify whether the obtained WB units are of adequate quality for use in anaemic patients. 
Conflict of interest The authors declared no potential conflicts of interest with respect to the research, authorship, and/ or publication of this article.

Funding The authors received no financial support for the research, authorship, and/or publication of this article.

\section{References}

1 Weingart C, Giger U and Kohn B. Whole blood transfusions in 91 cats: a clinical evaluation. J Feline Med Surg 2004; 6: 139-148.

2 Klaser DA, Reine NJ and Hohenhaus AE. Red blood cell transfusion in cats: 126 cases (1999). J Am Vet Med Assoc 2005; 226: $920-$ 923.

3 Lucas RL, Lentz K Dand Hale AS. Collection and preparation of blood products. Clin Tech Small Anim Pract 2004; 19 : 55-62.

4 Gibson G. Transfusion medicine. In: King L and Boag A (eds). BSAVA manual of canine and feline emergency and critical care. 2nd ed. Gloucester: British Small Animal Veterinary Association, 2007, pp 215-227.

5 Hohenhaus AE. Blood transfusion and blood substitutes. In: DiBartola SP (ed). Fluid, electrolyte, and acid-base disorders in small animal practice. 4th ed. St Louis, MO: Elsevier Saunders, 2012, pp 585-604.

6 Reed N, Espadas I, Lalor SM, et al. Assessment of five formulae to predict post-transfusion packed cell volume in cats. J Feline Med Surg 2014; 16: 651-656.

7 Wardrop KJ, Young J and Wilson E. An in vitro evaluation of storage media for the preservation of canine packed red blood cells. Vet Clin Pathol 1994; 23: 83-88.

8 Wardrop KJ, Owen TJ and Meyers KM. Evaluation of an additive solution for preservation of canine red blood cells. $J$ Vet Intern Med 1994; 8: 253-257.

9 Wardrop KJ, Russell LT and Mugnai K. Evaluation of canine red blood cells stored in a saline, adenine, and glucose solution for 35 days. J Vet Intern Med 1997; 11: 5-8.

10 Niinistö K, Raekallio M and Sankari S. Storage of equine red blood cells as concentrate. Vet J 2008; 176: $227-231$. 11 Spada E, Proverbio D, Bagnagatti De Giorgi G, et al. Clinical and haematological responses of feline blood donors anaesthetised with a tiletamine and zolazepam combination. J Feline Med Surg 2015; 17: 338-341.

12 AbbottCell-Dyn3500 System, Manual of use, rev. D-revision of the J software. Vol. I. Wiesbaden, Germany: Abbott, 2001.

13 Sowemimo-Coker SO. Red blood cell hemolysis during processing. Transf Med Rev 2002; 16: 46-60.

14 Harmening DM and Dietz Polansky V. Fundamental concepts. In: Harmening DM (ed). Modern blood banking and transfusion practices. 6th ed. Philadelphia, PA: FA Davis Company, 2012, pp 1-25.

15 Wong $C$ and Haskins SC. The effect of storage on the $\mathbf{P}_{50}$ of feline blood. J Vet Emerg Crit Care 2007; 17: 32-36.

16 Wellman ML, Di Bartola SP and Kohn CW. Applied physiology of body fluids in dogs and cats. In: Di Bartola SP (ed.). Fluid, electrolyte, and acid-base disorders in small animal practice. St Louis, MO: Elsevier Saunders, 2012, pp 2-25.

17 Kohn B and Weingart C. Feline transfusion medicine. In: Day MJ and Kohn B (eds). BSAVA manual of canine and feline haematology and transfusion medicine. 2nd ed. Gloucester: British Small Animal Veterinary Association, 2012, pp 308-318.

18 Hess JR. An update on solutions for red cell storage. Vox Sang 2006; 91: 13-19.

19 DiBartola SP. Electrolyte and acid-base disorders. In: Willard MD and Tvedten H (eds). Small animal clinical diagnosis by laboratory methods. St Louis, MO: Elsevier Saunders, 2012, pp 112-125.

20 Lin HC, Thurmon JC, Benson GJ, et al. Telazol - a review of its pharmacology and use in veterinary medicine. J Vet Pharmacol Therap 1993; 16: 383-418. 
21 Lacerda M, Sampaio R and Nunes T. Hematological and cardio-respiratory study in females dogs anesthetized with cetamines/xilazine and tiletamine/zolazepam sub- mitted to ovariohysterectomy [article in Portuguese]. Biosci J Uberlândia 2010; 26: 913918.

22 Dhumeaux MP, Snead ECR, Epp TY, et al. Effects of a standardized anesthetic protocol on hematologic variables in healthy cats. J Feline Med Surg 2012; 14: 701-705.

23 Zelmanovic $D$ and Hetherington EJ. Automated analysis of feline platelets in whole blood, including platelet count, mean platelet volume, and activation state. Vet Clin Pathol 1998; 27: 2-9.

24 Norman EJ, Barron RCJ, Nash AS, et al. Prevalence of low automated platelet counts in cats: comparison with prevalence of thrombocytopenia based on blood smear estimation. Vet Clin Pathol 2001; 30: 137-140.

25 Harvey JW. Veterinary hematology. A diagnostic guide and color atlas. St Louis, MO: Elsevier Saunders, 2012, pp 11-32.

26 Tschopp TB. Aggregation of cat platelets in vitro. Thromb Diath Haemorrh 1969; 23: 601-620.

27 Vermylen J and Deckmyn H. Antiplatelet agents: pharmacology and clinical use. In: Poller L (ed). Recent advances in blood coagulation. Edinburgh: Churchill Livingstone, 1993, pp 125-144.

28 Norman EJ, Barron RC, Nash AS, et al. Evaluation of a citrate-based anticoagulant with platelet inhibitory activity for feline blood cell counts. Vet Clin Pathol 2001; 30: 124-132.

29 Tvedten $\mathrm{H}$ and Thomas JS. General laboratory concepts. In: Willard MD and Tvedten H (eds). Small animal clinical diagnosis by laboratory methods. St Louis, MO: Elsevier Saunders, 2012, pp 1-11. 